\title{
Retrospective selection and sources of superior inbreds amongst pedigree inbred families of Nicotiana rustica
}

\author{
H. S. Pooni and \\ J. L. Jinks
}

Department of Genetics, University of Birmingham, P.O. Box 363, Birmingham B15 2TT, UK.

\begin{abstract}
A single cycle of selection in the $F_{2}, F_{3}, F_{4}$ and $F_{7}$ generations using the overall means of the individual hierarchies as their predicted breeding values, has been applied retrospectively to seven metrical traits scored on $784 \mathrm{~F}_{7}$ inbreds extracted from the cross of varieties 2 and 12 of Nicotiana rustica by the method of pedigree inbreeding. The hierarchical structure within $98 \mathrm{~F}_{2}$ groups each of $8 \mathrm{~F}_{7}$ families is further used to determine the distribution and source of the superior inbreds within each hierarchy. While the efficiency of selection improved steadily the more advanced the generations in which it was applied, superior recombinants originated more frequently in the early than in the late generations. The hierarchical method of inbreeding, however, favours the recovery of recombinants from the advanced generations and in the present case the two balance each other exactly. The improvement in response to selection in the advanced generations is completely associated with the relative reductions in error variances and is, therefore, not attributable to any genuine change in the genetic covariances.

The present investigation also confirms that single seed descent is the most cost effective method of producing inbreds from a cross until and unless there are some unforeseen advantages in operating selections in the initial stages of a breeding programme.
\end{abstract}

\section{INTRODUCTION}

There are no theoretical or practical reasons for preferring pedigree inbreeding to single seed descent for extracting random samples of recombinant inbred lines from a cross (Jinks and Pooni, $1981 a$, $1981 b, 1982,1984)$. Traditionally, however, pedigree inbreeding includes early generation assessment as a basis for selecting for an increase in the frequency of desirable genotypes.

Preliminary observations on characters of intermediate to low heritability suggest that the value of such selection is low (Brumpton. Boughey and Jinks, 1977; Jinks, Jayasekara and Boughey, 1977; Boughey and Jinks, 1978; Jinks and Pooni, $1981 a$ ). These observations have been repeated on a larger scale for the highly heterotic cross of varieties 2 and 12 of Nicotiana rustica using characters which display a wide range of heritabilities and amounts and kinds of genetical variation (Pooni, Jinks and Jayasekara, 1978).

\section{MATERIAL AND METHOD}

The material is $784 \mathrm{~F}_{7}$ families obtained by pedigree inbreeding from a random sample of 98 $\mathrm{F}_{2}$ plants of the cross of varieties 2 and 12 of Nicotiana rustica. Each original $F_{2}$ plant is represented by a random sample of 8 , hierarchically related, $\mathrm{F}_{7}$ families (see Jinks and Pooni, 1984 for details). The data consist of seven characters scored on eight replicates of each of the 784 families.

In a previous paper (Jinks and Pooni, 1984) we presented the frequencies of potentially useful recombinant inbred lines among the 784 families defining these as having mean performances which fell outside of the parental range $\left(\geqq \bar{P}_{1}, \leqq \bar{P}_{2}\right)$ or better than their heterotic $F_{1}$. We shall first examine the distribution of the superior inbreds within and between the $98 \mathrm{~F}_{2}$ groups of $8 \mathrm{~F}_{7}$ families that make up the 784 . Within each $F_{2}$ group we shall determine at which generation of the pedigree the superior families emerged.

Since we shall be identifying the superior recombinant inbred lines at the $F_{7}$, we shall also examine how much earlier in the breeding programme we could have identified those lineages which have yielded the higher than average frequencies of superior inbred lines. 


\section{RESULTS}

\section{Distribution of hierarchies}

Results of the preliminary classification of hierarchies according to their potential for producing 0 to 8 recombinant inbreds that show superior performance ( $\geqq \bar{P}_{1}$ or $\leqq \bar{P}_{2}$ ) are given for each character in table 1. It is clear from these results that the hierarchies are well spread between the nine classes (0 to 8$)$ with their frequencies showing a

Table 1 Classification of the 98 hierarchics of 8 inbred families according to the number of inbreds in each hierarchy which are superior $\left(\geq \bar{P}_{1}\right.$ or $\left.\subseteq \bar{P}_{2}\right)$ for each character

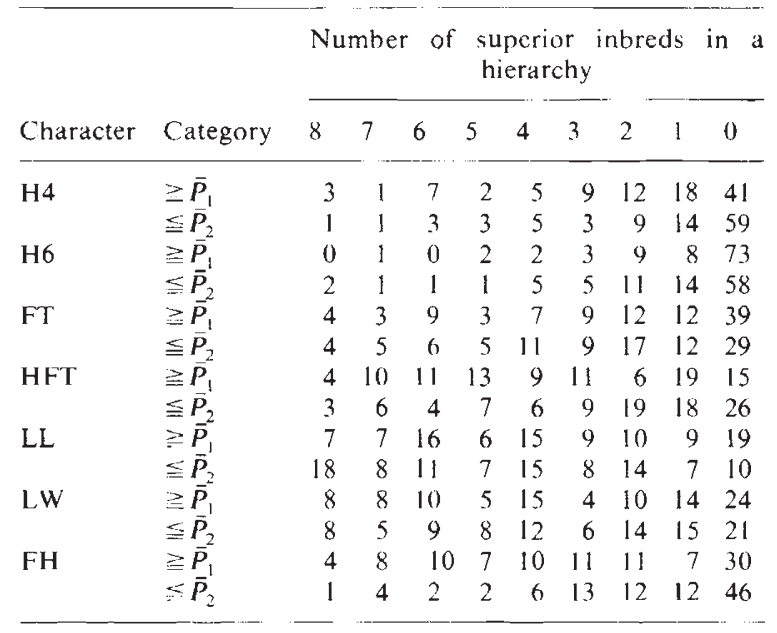

negative correlation with the number of superior inbreds in each class. In other words potentially superior hierarchies tend to be relatively rarer than the less potent hierarchies. The number of hierarchies falling into each class and their totals over classes with 1 to 8 superior inbreds also vary from character to character. These differences, however, depend exclusively on the degree of gene association in the parents and the amount of additive genetic variability which is present in the original cross.

Systematic labelling of each of the eight lineages within an hierarchy allows the 98 hierarchies to be cross classified on the basis of the source of origin of the superior inbreds. For example, hierarchies with 5 superior inbreds can be divided into three distinct groups where the sources of origin of these inbreds are:

1. One $F_{3}$ ancestor (giving 4 superior inbreds) and one $F_{5}$ ancestor (giving 1 superior inbred);

2. Two $\mathrm{F}_{4}$ ancestors (each giving 2 superior inbreds) and one $F_{5}$ ancestor (giving 1 superior inbred) and

3. One $\mathrm{F}_{4}$ ancestor (giving 2 superior inbreds) and three $F_{5}$ ancestors (each giving 1 superior inbred).

Similar groupings have been produced for the other classes. The results are tabulated in table 2 .

The relative importance of $F_{2}, F_{3}, F_{4}$ and $F_{5}$ segregation as diminishing sources of superior inbreds is quite apparent from table 2. For example

Table 2 Division of the 98 hierarchies of 8 inbred families (class 0 to 8 ) into groups according to the generation of origin (source) of the superior inbreds in cach lineage for each character

\begin{tabular}{|c|c|c|c|c|c|c|c|c|c|c|c|c|c|c|c|}
\hline Combir & & & $\mathrm{H} 4$ & & H6 & & FT & & $\begin{array}{l}\text { racter } \\
\text { IFT }\end{array}$ & & & & LW & & $\mathrm{FH}$ \\
\hline Class & Source & $\geq \bar{P}_{1}$ & $\leqq \bar{P}_{2}$ & $\geqslant \bar{P}_{1}$ & $\leq \bar{P}_{2}$ & $\geqq \bar{P}_{1}$ & $\leqq \bar{P}_{2}$ & $\geqq \bar{P}_{1}$ & $\leqq \bar{P}_{2}$ & $\because \bar{P}_{1}$ & $=\bar{P}_{2}$ & $\geq \bar{P}_{1}$ & $\leqq \bar{P}_{2}$ & $\geqq \bar{P}_{1}$ & $\leq \bar{P}_{2}$ \\
\hline 8 & $F_{2}$ alone & 3 & 1 & () & 2 & 4 & 4 & 4 & 3 & 7 & 18 & 8 & 8 & 4 & 1 \\
\hline 7 & $F_{2}+F_{5}$ & 1 & 1 & 1 & 1 & 3 & 5 & 10 & 6 & 7 & 8 & 8 & 5 & 8 & 4 \\
\hline $64+2$ & $\mathrm{~F}_{3}+\mathrm{F}_{4}$ & 3 & 2 & 0 & 1 & 3 & 0) & 6 & 2 & 10 & 3 & 4 & 3 & 6 & 1 \\
\hline $4+1+1$ & $\mathrm{~F}_{3}+\mathrm{F}_{5}$ & 0 & 0 & 0 & 0 & 5 & 2 & 4 & 1 & 2 & 7 & 4 & 3 & 3 & 1 \\
\hline $2+2+1+1$ & $F_{4}+F_{5}$ & 4 & 1 & 0 & 0) & 1 & 4 & 1 & 1 & 4 & 1 & 2 & 3 & 1 & 0 \\
\hline $54+1$ & $F_{3}+F_{3}$ & 0 & 1 & () & 1 & 1 & 3 & 8 & 4 & 4 & 2 & 3 & 3 & 3 & 1 \\
\hline $2+2+1$ & $F_{4}+F_{5}$ & 2 & 0 & 2 & 0 & 0 & 2 & 3 & 3 & 1 & 4 & 0 & 5 & 2 & 1 \\
\hline $2+1+1+1$ & $F_{4}+F_{5}$ & 0 & 2 & 0 & 0 & 2 & 0 & 2 & 0 & 1 & 1 & 2 & 0 & 2 & 0 \\
\hline 44 & $\mathrm{~F}_{3}$ alone & 2 & 4 & 1 & 3 & 5 & 4 & 5 & 3 & 7 & 6 & 7 & 4 & 7 & 4 \\
\hline $2+2$ & $\mathrm{~F}_{4}$ alone & 0 & 1 & 0 & 1 & 1 & 1 & 0 & 0 & 2 & 2 & 5 & 2 & 0 & 1 \\
\hline $2+1+1$ & $\mathrm{~F}_{4}+\mathrm{F}_{5}$ & 3 & 0 & 1 & 1 & 1 & 5 & 3 & 3 & 6 & 7 & 3 & 5 & 3 & 1 \\
\hline $1+1+1+1$ & $\mathrm{~F}_{5}$ alone & 0 & 0 & 0 & 0 & 0 & 1 & 1 & 0 & 0 & 0 & 0 & 1 & 0 & 0) \\
\hline $32+1$ & $\mathrm{~F}_{4}+\mathrm{F}_{5}$ & 7 & 2 & 3 & 4 & 8 & 74 & 7 & 9 & 8 & 6 & 4 & 5 & 9 & 10 \\
\hline $1+1+1$ & $F_{s}$ alone & 2 & 1 & 0 & 1 & 1 & 5 & 4 & 0 & 1 & 2 & 0 & 1 & 2 & 3 \\
\hline 22 & $\mathrm{~F}_{4}$ alone & 6 & 5 & 7 & 7 & 6 & 8 & 5 & 12 & 4 & 10 & 5 & 9 & 6 & 8 \\
\hline $1+1$ & $\mathrm{~F}_{S}$ alone & 6 & 4 & 2 & 4 & 6 & 9 & 1 & 7 & 6 & 4 & 5 & 5 & 5 & 4 \\
\hline 1 & $F_{5}$ alone & 18 & 14 & 8 & 14 & 12 & 12 & 19 & 18 & 9 & 7 & 14 & 15 & 7 & 12 \\
\hline 0 & & 41 & 59 & 73 & 58 & 39 & 29 & 15 & 26 & 19 & 10 & 24 & 21 & 30 & 46 \\
\hline
\end{tabular}


the sources identified with segregation in the $F_{2}$ and $F_{3}$ generations occur with a higher frequency among the hierarchies than those identified in the $F_{4}$ and $F_{5}$. While this is expected because of a predictable reduction in the level of heterozygosity in the successive generations of a selfing programme these differences are also enhanced by the number of inbreds attributable to each source and the probability with which different events occur. For instance a superior recombinant contributes 8 superior inbreds when its source is the $\mathrm{F}_{2}$ generation. The same recombinant, however, contributes only 4 superior inbreds when its source is the $F_{3}$ generation and its contributions are further reduced to 2 and 1 superior inbreds in the $F_{4}$ and $\mathrm{F}_{5}$, respectively. On the other hand the chances of recovery of such a recombinant multiply twofold in each successive generation because we are doubling the number of lines from 98 in $F_{2}$ to 196 in $F_{3}, 392$ in $F_{4}$ and 784 in $F_{5}$. Therefore, if we wish to isolate the effects of selfing in the $F_{2}, F_{3}$, $\mathrm{F}_{4}$ and $\mathrm{F}_{5}+\mathrm{F}_{6}$ generations we must consider only the frequencies that are attributable exclusively to $\mathrm{F}_{2}$ alone in class $8, \mathrm{~F}_{3}$ alone in class $4, \mathrm{~F}_{4}$ alone in class 2 and $F_{5}$ alone in class 1 . These frequencies, which are $0.0488,0.0226,0.0179$ and 0.0163 respectively approximate to $\frac{1}{2}: \frac{1}{4}: \frac{1}{8}: \frac{3}{32}$, the proportions of the additive genetic variance that the $F_{2}$, $F_{3}, F_{4}$, and $F_{5}+F_{6}$ generations contribute to the total variance of the final inbreds. In fact the first pair of values $(0.0488$ and 0.0226$)$ are relatively smaller than their expected values and those of the second pair $(0.0179$ and 0.0163$)$ relatively larger. Again these differences are expected because the additive genetic variances $\left(D_{1}\right.$ and $\left.D_{2}\right)$ attributable to the $F_{2}$ and $F_{3}$ generations are observed to be smaller than those attributable to later generations $\left(D_{3}\right.$ and $\left.D_{4}+D_{5}\right)$ for most of the characters due to the presence of repulsion linkages (Jinks and Pooni, 1984).

Two further categorisations of the 98 hierarchies one based on the overall means of the hierarchies and the other on the upper and lower limits of the range of inbred means in each hierarchy are tabulated in table 3 . The first divides the hierarchies into three categories each corresponding with $\geqq \bar{P}_{b}$, $\leqq \bar{P}_{2}$ and the remainder. The second categorises hierarchies into six groups whose upper and lower limits are defined as $\geqq \bar{P}_{1} \geqq \bar{P}_{1} \geqq \bar{P}_{1}>\bar{P}_{2}$, $\bar{P}_{2} \leqq \bar{P}_{2}$, $<\bar{P}_{1}, \leqq \bar{P}_{2}, \geqq \bar{P}_{1} \leqq \bar{P}_{2}$ and $\left\langle\bar{P}_{1}>\bar{P}_{2}\right.$, respectively. This allows the hierarchies to be divided into high scoring less variable, high scoring more variable, low scoring less variable, low scoring more variable, highly variable and intermediate categories. This categorisation is specifically used to cross
Table 3 Categories of the 98 hierarchies according to their overall means and according to the overall range displayed by the inbred means derived from each hierarchy for each character

\begin{tabular}{|c|c|c|c|c|c|c|c|c|}
\hline \multicolumn{2}{|c|}{ Limits } & \multicolumn{7}{|c|}{ Character } \\
\hline Upper & Lower & $\mathrm{H} 4$ & H6 & FT & HFT & LL & LW & $\mathrm{FH}$ \\
\hline \multicolumn{9}{|c|}{ (a) Overall means of the hierarchies } \\
\hline$\geqq \bar{P}_{1}$ & - & 18 & 4 & 25 & 45 & 42 & 33 & 31 \\
\hline- & $\leqq \bar{P}_{2}$ & 5 & 7 & 22 & 21 & 56 & 36 & 10 \\
\hline$<\vec{P}_{1}$ & $>\bar{P}_{2}^{2}$ & 75 & 87 & 51 & 32 & 0 & 29 & 57 \\
\hline \multicolumn{9}{|c|}{ (b) Range of inbred means in each hierarchy } \\
\hline$\geqq \tilde{P}_{i}$ & $\geqq \bar{P}_{i}$ & 3 & 0 & 4 & 4 & 7 & 8 & 4 \\
\hline$\geqq \bar{P}_{i}^{i}$ & $>\bar{P}_{2}$ & 45 & 22 & 25 & 22 & 3 & 22 & 38 \\
\hline$\leqq \bar{P}_{2}^{\prime}$ & $\leqq \bar{P}_{2}$ & 1 & 2 & 4 & 3 & 18 & 8 & 1 \\
\hline$<\overline{\boldsymbol{P}}_{1}^{2}$ & $\leqq \bar{P}_{2}$ & 29 & 35 & 35 & 12 & 1 & 15 & 25 \\
\hline$\geqq \overline{\boldsymbol{P}}_{1}$ & $\leqq \bar{P}_{2}$ & 9 & 3 & 30 & 57 & 69 & 54 & 26 \\
\hline$<\bar{P}_{1}^{2}$ & $>\bar{P}_{2}$ & 11 & 36 & 0 & 0 & 0 & 1 & 4 \\
\hline
\end{tabular}

classify hierarchies which fall under the $\geqq \bar{P}_{1} \leqq \bar{P}_{2}$ group because previously they were counted twice, once in the $\geqq \bar{P}_{1}$ and then in the $\leqq \bar{P}_{2}$ class (see table 1).

The proportions of hierarchies that fall into the three categories on the basis of their overall means is similar to those for inbred lines derived from the same cross by single seed descent (see table 5 of Jinks and Pooni, 1984) except that for every character the relative numbers in the $\geqq \bar{P}_{1}$ and $\leqq \bar{P}_{2}$ categories are always less than those of the SSD lines. This is expected because the total genetic variance present amongst the hierarchy means $\left(\frac{1}{2} D_{1}+\frac{1}{8} D_{2}+\frac{1}{32} D_{3}+\frac{1}{128} D_{4}+\cdots=\frac{43}{64} D\right)$ is significantly smaller than that present amongst the random inbreds extracted by single seed descent $\left(\frac{1}{2} D_{1}+\right.$ $\left.\frac{1}{4} D_{2}+\frac{1}{8} D_{3}+\frac{1}{16} D_{4}+\cdots=D\right)$.

There are many hierarchies with a small range coupled with extreme performance ( $\geqq \bar{P}_{1} \geqq \bar{P}_{1}$ and $\leqq \bar{P}_{2} \leqq \bar{P}_{2}$ ) and only few with a high or low performance coupled with a large range. The differences between the $\geqq \bar{P}_{1} \geqq \bar{P}_{1}$ and $\geqq \bar{P}_{1}>\bar{P}_{2}$, and $\leqq \bar{P}_{2} \leqq \bar{P}_{2}$ and $\left\langle\bar{P}_{1} \leqq \bar{P}_{2}\right.$ categories depend directly on the proportion of the additive genetic difference between the parents $\left(\bar{P}_{1}\right.$ and $\left.\bar{P}_{2}\right)$ that results in a net difference between their means, that is, the degree of gene association in the parents. Consequently the numbers of hierarchies falling into each of the six categories in table 3(b) should be highly correlated with the degree of gene association in the absence of complications such as epistasis and genotype $x$ environmental interactions. These correlations over characters take the values of $-0.8278,0 \cdot 5020^{\mathrm{NS}},-0.6016^{\mathrm{NS}}, 0 \cdot 8613,-0.9406$ and 0.8030 for categories 1 to 6 , respectively (see table 3 ). 


\section{Selection amongst lineages}

The $784 \mathrm{~F}_{7}$ families used in the present experiment were produced during a short span of three years starting in the summer of 1978 when the $98 \mathrm{~F}_{2}$ plants of the $V_{2} \times V_{12}$ cross were raised in a field experiment and selfed. While the material was rapidly advanced at the rate of two generations per year the performances of the $98 \mathrm{~F}_{3}$ and $196 \mathrm{~F}_{4}$ families were assessed during the summer of 1980 when the two generations were raised in two separate experiments. We can, therefore, apply selection to the $F_{2}, F_{3}$ and $F_{4}$ data retrospectively to find out if selection in these early generations increases the chances of retaining lineages with superior inbreds. Only one cycle of selection on individual traits has, however, been applied. Multicycle/multi-trait selection will be the subject of a further paper.

The selection criterion we apply is relatively simple. For each character we take the phenotypic scores of the $98 \mathrm{~F}_{2}$ individuals and select the 5 highest and 5 lowest scoring phenotypes. We then trace the descendents of the selected phenotypes through to the $F_{7}$ generation and assess their average performance by obtaining the overall mean of the hierarchies of families to which they give rise. We apply the same selection criteria to the $F_{3}, F_{4}$ and $F_{7}$ generations and make the results comparable by selecting only amongst the 98 hierarchy means. The results of these selections are presented in table 4.

Also given for comparison are the average performances of the 5 highest scoring and 5 lowest scoring inbred lines that are present amongst the
60 inbreds extracted from the $V_{2} \times V_{12}$ cross by the method of single seed descent (Pooni, Jinks and Jayasekara, 1978).

Selection in the early generations of a pedigree breeding programme requires assessment of the relevant material under field conditions by conducting an appropriately designed experiment and scoring for all of the quantitative and qualitative characters under selection. This in turn makes extra demands on manpower, financial resources and facilities compared with inbreeding without selection. Assessments of the manpower requirements for the Nicotiana rustica experiment, which is the largest component of the cost, are listed in table 5. Also given in table 5 are the comparative requirements for producing seed by selfing the same number of families by the method of single seed descent.

\section{CONCLUSIONS}

The main conclusion we can draw from the first part of "Results" is that each cycle of recombination makes an important and an approximately equal contribution to the production of superior inbreds (see tables 1,2 and 3). While superior recombinants in the $F_{2}$ and $F_{3}$ generations are essential for obtaining superior hierarchies that have a majority of inbreds ( 5 or more out of 8 ) with a superior performance defined as $\geqq \bar{P}_{1}$ or $\leqq \bar{P}_{2}$, the recombination in the $F_{4}$ and $F_{5}$ generations generates disproportionately large numbers of superior inbreds in spite of the predictable reduction in heterozygosity. This is because the

Table 4 Average $F_{7}$ performances of the selections made in the $F_{2}, F_{3}, F_{4}$ and $F_{7}$ generations and in the SSD inbred lines, overall mean of the 98 lineages and the $h_{n}^{2}$ values for each character

\begin{tabular}{|c|c|c|c|c|c|c|c|}
\hline $\begin{array}{l}\text { Method of } \\
\text { Selection }\end{array}$ & $\mathrm{H} 4$ & H6 & FT & $\begin{array}{l}\text { Characters } \\
\text { HFT }\end{array}$ & LL & LW & $\mathrm{FH}$ \\
\hline \multicolumn{8}{|c|}{ (a) Selection for high mean } \\
\hline 2. $F_{3}$ fam. means & $21 \cdot 52$ & $62 \cdot 01$ & $42 \cdot 26$ & $85 \cdot 36$ & $23 \cdot 81$ & 19.91 & 159.97 \\
\hline 3. $\overrightarrow{F_{4}}$ hier. means & $24 \cdot 45$ & $65 \cdot 24$ & $43 \cdot 72$ & $94 \cdot 84$ & $25 \cdot 36$ & $21 \cdot 52$ & $166 \cdot 25$ \\
\hline 4. $\mathrm{F}_{7}$ hier. means & $25 \cdot 09$ & $67 \cdot 85$ & $43 \cdot 72$ & $99 \cdot 52$ & $26 \cdot 59$ & $22 \cdot 47$ & $170 \cdot 06$ \\
\hline \multicolumn{8}{|c|}{ (b) Selection for low mean } \\
\hline 1. $F_{2}$ plants & $4 \cdot 79$ & $32 \cdot 91$ & $16 \cdot 53$ & -- & $19 \cdot 26$ & $15 \cdot 37$ & $109 \cdot 27$ \\
\hline 2. $F_{3}$ fam. means & $8 \cdot 26$ & $31 \cdot 49$ & $15 \cdot 39$ & $44 \cdot 12$ & $19 \cdot 81$ & $15 \cdot 92$ & $99 \cdot 65$ \\
\hline 3. $\mathrm{F}_{4}$ hier. means & $5 \cdot 45$ & $28 \cdot 09$ & 13.77 & $40 \cdot 63$ & $17 \cdot 89$ & $12 \cdot 36$ & $93 \cdot 33$ \\
\hline 4. $F_{7}$ hier. means & 4.51 & $22 \cdot 14$ & $13 \cdot 21$ & $40 \cdot 34$ & $17 \cdot 04$ & $11 \cdot 44$ & $90 \cdot 66$ \\
\hline 5. SSD & $4 \cdot 10$ & $20 \cdot 41$ & $13 \cdot 44$ & $40 \cdot 79$ & $15 \cdot 49$ & $10 \cdot 59$ & $86 \cdot 19$ \\
\hline
\end{tabular}

* measurements on HFT were not recorded in 1978. 
Table 5 Costs of seed production and field assessment of $N$. rustica

\begin{tabular}{|c|c|c|}
\hline Operation & Detail & $\begin{array}{l}\text { Cost } \\
\text { (man } \\
\text { days) }\end{array}$ \\
\hline \multicolumn{3}{|c|}{ (a) Seed production (cost per 800 selfs) } \\
\hline 1. Pre-sowing & Preparing labels, seeds, pots & 3 \\
\hline 2. Sowing & Sowing 1600 pots & 3 \\
\hline 3. Management & $\begin{array}{l}\text { Watering, spraying, general } \\
\text { maintenance }\end{array}$ & 7 \\
\hline 4. Seed production & $\begin{array}{l}\text { Bagging, selfing, collecting } \\
\text { capsules, thrashing, etc. }\end{array}$ & $\begin{array}{r}9 \\
22\end{array}$ \\
\hline \multicolumn{3}{|c|}{ (b) Experiment (of 4000 plants and 4 months duration) } \\
\hline 1. Pre-sowing & $\begin{array}{l}\text { Label preparations }(2) \\
\text { randomisation }(5), \text { seed } \\
\text { packets }(2), \text { bench prep. }(2)\end{array}$ & 11 \\
\hline 2. Sowing & $\begin{array}{l}\text { Soil sterilisation (1), soil } \\
\text { mixing (1), pot filling (4), } \\
\text { sowing (8) }\end{array}$ & 14 \\
\hline 3. Post-sowing & $\begin{array}{l}\text { Transplanting (1), thinning (2), } \\
\text { watering and general } \\
\text { maintenance }(3)\end{array}$ & 6 \\
\hline $\begin{array}{l}\text { 4. Cold-frame } \\
\text { weather hardening }\end{array}$ & $\begin{array}{l}\text { Transfer }(2) \text { and general } \\
\text { maintenance }(2)\end{array}$ & 4 \\
\hline 5. Planting & $\begin{array}{l}\text { Preparing field labels }(1) \\
\text { marking field (3), } \\
\text { planting (10) }\end{array}$ & 14 \\
\hline 6. Post-planting & $\begin{array}{l}\text { Watering (2), hoeing and weed } \\
\text { control (6), disposal (4) }\end{array}$ & $d 2$ \\
\hline 7. Data recording & $\begin{array}{l}\text { Average } 4 \text { hours/day for } \\
60 \text { days }\end{array}$ & 30 \\
\hline \multirow[t]{2}{*}{ 8. Data processing } & $\begin{array}{l}\text { Punching cards (4), } \\
\text { checking (2), preliminary } \\
\text { analysis (2) prior to } \\
\text { making selections }\end{array}$ & 8 \\
\hline & Total & 99 \\
\hline
\end{tabular}

hierarchical system of inbreeding allows more chances of recovering recombinants in the more advanced than in the early generations. In the bifurcating system used in our experiment the chances of recovering recombinants doubles every generation. On the other hand, the frequency of recombinants is much higher in the early generations and in the present case these two opposing trends balance each other exactly. Consequently the proportions of superior inbreds arising from segregation in the various generations are approximately equal.

It is also clear from table 3 that nearly all of the $98 \mathrm{~F}_{2}$ and $196 \mathrm{~F}_{3}$ plants chosen for further selfing were heterozygous. Virtually none of the lineages have therefore attained complete homozygosity in the early generations. Conversely none of these $F_{2}$ and $F_{3}$ plants appears to be heterozygous at as many loci as the original $F_{1}$ because not a single hierarchy has inbred lines that display variability comparable to that of the single seed descent lines extracted from the same cross. This may, however, in part be attributable to the sample of inbred lines per hierarchy being only 8 compared with a sample of 60 SSD inbreds.

A significant conclusion which we draw from the second part of "Results" is that selection is effective in every generation although its efficiency increases steadily the later the generation in which it is imposed. The efficiency, however, increases much more for characters with low than with high heritabilities. The present results therefore differ from those for the $V_{1} \times V_{5}$ cross which has lower levels of heritability (Jinks and Pooni, 1981 $a$ ). Further, the method of selection we have applied is particularly designed to show the influence of error variations on the efficiency of selection. The genetic covariance between the phenotypes in the selection generation and the overall mean of the corresponding lineages in the $F_{7}$ is constant and equal to $\simeq \frac{1}{2} \mathrm{D}$ and only their correlations vary because the genetic and environmental variances of the $F_{2}, F_{3}$ and $F_{4}$ generations differ.

With qualitative characters materials can often be screened under glasshouse or small scale pot or field experiments. Rigorous selection is normally applied to quantitative characters, however, only after a large scale field assessment. The modest sized $N$. rustica experiment which we have had to conduct to apply one cycle of selection, including seed production $(99+22$ man days), costs almost 6 times the manpower that is required for advancing one generation of inbreeding by single seed descent ( 22 man days). Therefore, until and unless there are some clear advantages in imposing selections in the initial stages of a breeding programme such as better truncation levels for multiple traits, single seed descent is the most cost effective method for producing inbreds from a cross.

\section{REFERENCES}

BOUGHEY, H. AND JINKS, J. L. 1978. Joint selection for both extremes of mean performance and of sensitivity to a macro-environmental variable. III. The determinants of sensitivity. Heredity, 40, 363-369.

BRUMPTON, R. J., BOUGHEY, H. AND JINKS, J. L. 1977. Joint selection for both extremes of mean performance and of sensitivity to a macro-environmental variable. I. Family selection. Heredity, 30, 219-226.

JINKS, J. L. AND POONI, H. S. 1981a. Comparative results of selection in early and late stages of an inbreeding programme. Heredity, 46, 1-7. 
JINKS, J. L. AND POONI, H.S. 1981 b. Properties of pure breeding lines produced by dihaploidy, single seed descent and pedigree breeding. Heredity, 46, 391-395.

JINKS, J. L. AND POONI, H. S. 1982. Predicting the properties of pure breeding lines extractable from a cross in the presence of linkage. Heredity, 49, 265-270.

JINKS, J. L. AND POONI, H. S. 1984. Comparison of inbred lines produced by single seed descent and pedigree inbreeding. Heredity, 53, 299-308.
JINKS, J. L., JAYASHKARA, N. E. M. AND BOUGHEY, H. 1977. Joint selection for both extremes of mean performance and of environmental sensitivity to a macro-environmental variable. II. Single seed descent. Heredity, 39, 345-355.

POONI, II. S., JINKS, J. L. AND JAYASEKARA, N. F. M. 1978. An investigation of gene action and genotype $x$ environment interaction in two crosses of Nicotiana rustica by triple test cross and inbred line analysis. Heredity, 38, 237-251. 